\title{
BENEFITS AND SUCCESS FACTORS OF OPEN-SOURCE WEB SERVICES DEVELOPMENT PLATFORMS FOR SMALL SOFTWARE HOUSES
}

\author{
Valter de Assis Moreno Junior \\ Ibmec-RJ, Brazil \\ Josir Cardoso Gomes \\ RADIX Educational Institute, Brazil
}

\begin{abstract}
It is usually difficult for companies to keep up with the development of new information technologies and adapt to them in face of the opportunities and threats their advances may represent. This is especially true for small and medium enterprises (SME) in emerging economies, where resources tend to be scarce and markets more volatile. This paper describes an action research conducted in a small Brazilian software house that adopted an open-source Web Services development platform in order to improve its software development process. Data analysis revealed critical success factors (CSF) in the adoption process, as well as specific benefits and barriers prone to be faced by small software houses in their adoption efforts. In the process of overcoming such barriers, SME may acquire intellectual capital that represents an essential resource to ensure their competitiveness and survival in emerging economies.
\end{abstract}

Keywords: Open-source, Web Services, Small and Medium Enterprises, Software Development, Emerging Economies

\footnotetext{
Manuscript first received/Recebido em 20/06/2011 Manuscript accepted/Aprovado em: 15/08/2012

Address for correspondence / Endereço para correspondência

Valter de Assis Moreno Jr., Faculdades Ibmec-RJ, Brazil. Possui graduação em Engenharia Eletrônica pelo Instituto Tecnológico de Aeronáutica - ITA (1988), mestrado em Engenharia de Produção pela Universidade Federal Fluminense - UFF (1993) e doutorado em Business Administration pela University of Michigan (2001). Atualmente é Professor Adjunto de Sistemas de Informação das Faculdades Ibmec do Rio de Janeiro.

Josir Cardoso Gomes, Brazil, has a Bachelor degree in Information Technology from FACHA (1998), a M.Sc. degree in Business Administration from Faculdades IBMEC - RJ (2005). Josir has extensive professional experience in Software Development and has been teaching and conducting research on issues related to the impact of Information Technology in organizations, the acceptance of management information systems by their users, Data Mining and Software Development best practices. He is currently the owner of Curso Radix in Rio de Janeiro.
} 


\section{INTRODUCTION}

In order to meet an increasing need for information storage, recovery and exchange in companies, IS researchers and professionals have been looking into new information systems development (ISD) tools, methods and techniques. The traditional client/server architecture that is still widely adopted by organizations around the world tends to hinder the implementation of faster business strategies due to the difficulties it presents to the adjustment and innovation of business processes and products (Hagel, 2004). Frequently, IT management has to resort to integrated software packages with high costs and deep impact on several areas of the organization (e.g.; structure, processes, skills, relationships). To address such problems, the architectures based on components and, more recently, on services (SOA - Service Oriented Architecture) have been developed by the software industry, aiming at the improvement of ISD processes and a better alignment with ever changing business needs.

Web Services (WS) technology has evolved as a standard platform to implement service-oriented architectures. In a recent survey (Krill, 2008), 53\% of 200 companies worldwide stated that they already were using SOA. In Yen's (2006) review of previous surveys conducted in the corporate setting, Web Services appeared as the most used component of SOA $(71 \%)$ and as the preferred way of standardizing it $(57 \%)$. Respondents of one of the studies mentioned the following reasons for adopting SOA/WS: standardization (60\%), business process automation (59\%), business flexibility (52\%), operational savings $(48 \%)$, and better integration with business partners (43\%) (Yen, 2006, p. 1031). It is important to note that small businesses, as well as large organizations, can take advantage of WS technology to increase flexibility, improve customer service and reduce costs (e.g., Ray \& Ray, 2006). For instance, Web Services have become an important resource to leverage the benefits of social networks to both users and companies (e.g., Enders et al., 2008; Paredes-Valverde et al., 2012). Social networks, such as Facebook, Twitter and Linkedin have been growing exponentially over the last decade (Henrikson, 2011), and are increasingly seen by organizations as critical channels to reach and understand their customers, collaborate and share knowledge, and conduct business (e.g., Pookulangara \& Koesler, 2011).

Software development and consulting companies that respond promptly to the opportunities brought about by WS technology will possibly establish a competitive advantage in their markets. In particular, small software houses that create, use and reuse web services to built customized solutions for their clients may be able to capture important benefits such as increased productivity and customer satisfaction (Lee, Olson \& Lee, 2009; W3C, 2004; Yen, 2006), thereby improving their competitiveness. However, SME are traditionally hindered by small budgets and limited technical expertise (Ray \& Ray, 2006), which may prevent them from pursuing WS alternatives effectively. This problem is even more serious in emerging economies, which are usually characterized by volatile markets, inadequate infrastructures, and scarce resources, and where SME usually account for a large proportion of the workforce. Paradoxically, in such harsh conditions, small business survival rates tend to be dismal. For instance, in Brazil, micro and small enterprises accounted for $98 \%$ of the 5.1 million companies that operated in the country in 2006, over $60 \%$ of the private sector's workforce, and $20 \%$ of the GNP (SEBRAE-SP, 2009). However, around $50 \%$ of Brazilian SMEs tend to close their doors before their third year of operation (SEBRAESP, 2009). 
In general, it is argued that, to maintain competitiveness, SME must reduce costs while fulfilling customers' expectations (c.f. SEBRAE-SP, 2009). In the case of software houses, open-source WS ISD architectures may facilitate the accomplishment of this objective, not only by decreasing licensing expenses, but also by allowing a better alignment with the customer's business requirements (e.g., functionality, time to complete the project, costs, etc.) and developing more innovative products (Lamastra, 2009; Lee, Olson \& Lee, 2009; W3C, 2004; Yen, 2006). In spite of the potential benefits of this technology, scholars have given little attention to its investigation in the context of small ISD businesses. For this reason, knowledge on the factors that condition the success of its adoption in this particular setting is still scarce.

As an initial attempt to close this gap, this paper reports the major findings of an exploratory action research (Thiollent, 1997; Baskerville \& Wood-Harper, 1996) that investigated the adoption of a WS open-source ISD platform by a small software house in Brazil. One of the authors was responsible for facilitating the introduction of WS standards, techniques and open-source tools in the company, as well as for collecting data for the research. The other author was mostly involved in data analysis, always keeping in check the possibility of the first one introducing any bias due to his personal involvement in the project. Critical success factors of WS open-source development technology adoption, as well as its potential benefits and pitfalls were identified. Their relevance to the particular context of SME in emerging economies is highlighted in the conclusion of the paper.

\section{WEB SERVICES AND SOA}

In SOA, software components are offered as services in a computer network, and can be integrated and used for different applications and purposes. Roughly, in such architecture, the development of new applications would consist of selecting appropriate services and orchestrating them according to relevant business rules. In this way, SOA could allow a faster, simpler and less expensive implementation of new business requirements in the organization's information systems. This claim is supported by the findings reported by Yen (2006, p. 1031), which included benefits of SOA adoption such as an easier and less expensive internal and external integration, a faster delivery of products, a more flexible application development, true reusability, and increased revenue and customer satisfaction.

Since the 2000's, the World Wide Web Consortium (W3C) has strived to develop and promote computer-based architecture that improves support conditions and integration among companies (W3C, 2004). This architecture, named Web Services (WS), defines open standards and open protocols that are able to advance the integration of loosely coupled applications (Sleeper, 2001; Iyer et al., 2003). Over the last decade, WS seems to have become the prevalent way of implementing SOA in the corporate setting (Yen, 2006). As such, WS may change the way information systems are modulated, distributed and purchased by organizations (Clabby, 2002).

The appeal of WS to IT and business managers derives from its prospective strategic and operational benefits. WS may add significant opportunities to the traditional economic model of software development. Its flexibility allows organizations to use their current infrastructure to implement new business models and develop new products and services, which can be offered through the Internet to a vast number of potential customers. Companies not only can make information available to external 
partners, but also sell their own internal services to other organizations that have similar needs (Booch, 2001; Lim \& Wen, 2003). Additionally, WS enhances interconnectivity and supports integration with legacy systems. This, together with the fact that it is based on open standards and technologies, suggests that WS can help organizations reduce time and costs associated with managing, maintaining, adjusting and developing their information systems. It is important to highlight that WS benefits are not restricted to the realms of large companies, but may also be reaped by SMEs that "use web services to effectively leverage other organizational resources such as agility and customer service” (Ray \& Ray, 2006, p. 287).

Nevertheless, as recently developed technologies, WS and SOA still require improvements. Although new frameworks were proposed to overcome some of their limitations, issues related to security, coordination, transactions and Business Process Management (BPM) aspects are still reported in the literature (e.g.; BNET, 2005; Kreger, 2003; Papazoglou \& Heuvel, 2007). Moreover, the interoperability premise, one of the pillars of service-oriented architecture, has been questioned by some authors (Stal, 2003). Such issues may pose a threat to the adoption of WS, especially for companies that lack adequate resources and technological expertise in volatile business environments.

\section{OPEN-SOURCE SOFTWARE}

The term "open source" is linked to the creation of a civic organization called the Free Software Foundation (FSF) by Richard Stallman in 1985. This organization was a milestone for the so-called "information society", as it put forth one of the most important civil actions organized in defense of freedom of information in recent history (Stallman, 1996). According to Stallman (1996), "free software refers to users' freedom to run, copy, distribute, study, change and improve the software". His concept is in fact quite similar to the Open Source Initiative's (OSI) definition of "open source", although the latter does not seem to be underpinned by the moral or ethical issues that characterize the Free Software Foundation's discourse. Indeed, the views purported by OSI do not establish that open-source products are always free of costs or that those who produce open-source software cannot sell and have financial gains from the products they develop.

By misconceiving open-source solutions as software that is necessarily free, many business owners have not given the proper importance to potential business models that emerged in the software industry (Kavanagh, 2004). However, as time passed by, opensource began to be seen as an appealing alternative, especially for companies that felt strangled by the monopolistic and high cost models practiced by large players in the software industry (e.g., US-DOJ, 1994; Kavanagh, 2004).

The attractiveness of open-source software has grown steadily with the advent of the Linux operating system. Based entirely on free software, Linux proved to be effective in problems that MS Windows operating systems could not solve or solved poorly or that were very costly (Kavanagh, 2004). Another successful example of the open-source phenomenon is the Apache Web server, which manages and provides access to Internet Web pages. Initially created by the Apache Foundation, the software has been continuously developed by a large community of programmers and analysts who spontaneously contribute their time to the project. A recent survey found that almost $70 \%$ of the servers on the Internet used Apache (Netcraft, 2011). 
There are several ways to generate revenue with open-source software, the most direct one being to sell a product. Open-source software can be distributed freely or may be sold the same way as proprietary software. However, when an open-source product is sold, the seller must provide the source code along with the product delivered (Fitzgerald \& Kenny, 2003). This way, another programmer can use the source code to understand how the system works and even modify it without having to hire or pay royalties to the original vendor. Another form of generating revenue is to provide services, support and training for applications and systems that are freely distributed (Fitzgerald \& Kenny, 2003). In the last decades, a number of companies have specialized and been quite successful in installing and configuring freely distributed open-source software, such as IBM, Sun/Oracle, Compiere, and SugarCRM.

The development and adoption of open-source software can generate additional benefits to companies, besides the savings related to license costs. Balestrin (2004), for instance, suggests that as companies take part in the networks of free software developers, they may acquire and share knowledge, and thus reduce the costs and risks involved in new product research and development, as well as in solving other organizational problems. Moreover, Balestrin (2004) highlights that those networks favor the concentration of efforts without depriving the strategic freedom of action of its members (p. 242). As they organize in networks, open-source software developers can also work together to obtain new customers and promote marketing initiatives that they would not be able to pursue individually. Networks that are structured under the aegis of a larger organization may also help developers improve their image among potential customers and obtain legitimacy in the larger institutional environment (Balestrin, 2004).

Open-source software has been increasingly accepted as an economically viable solution for companies in general. In fact, even large software companies, such as IBM and Google, have started to "open" the code of their products to increase their visibility and adoption, as well as to foster their improvement with the lowest possible cost (Fitzgerald, 2006; Santos Jr, 2008, 2010). Interestingly, the diffusion of open-source products seems to be due to a great extent to government efforts around the world. For example, the mayor of Munich leads one of the largest deployments of free software known until now, replacing Microsoft systems for open systems in more than fourteen thousand workstations (Dumout, 2004). In Brazil, the federal government has long stated its intention to use free software whenever possible (Brasil, 2011). In 2003, it established the Technical Committee for Free Software Implementation (CISL) to promote the use and development of free software in the federal offices. A recent survey conducted by the committee found that, seven years later, about half of the government agencies, state banks, public universities, and other bureaus have already switched their electronic mail, internet servers, information systems, desktop operating system, and office automation suites to open software, and that many others are carrying on projects to migrate in the near future.

Few studies have addressed the development and adoption of open-source software in Brazil. Carvalho and Campos (2009), for instance, compared open-source and proprietary Enterprise Resource Planning (ERP) systems, highlighting that SME would benefit from the lower costs and wider support options related to an open-source solution. However, they call attention to possibility of companies obtaining low quality services due to budget restrictions and the lack of IT resources that usually characterize small businesses. The other papers found in the literature describe successful 
applications in industries as diverse as healthcare (e.g., Santos Jr, 2010; Felix et al., 2009) and education (Jordan, Nohama \& Britto Junior, 2009; Roloff \& Oliveira, 2007). The searches conducted for the present research were unable to locate any studies on the usage or adoption of open-source development platforms by small and medium software development companies in Brazil.

Similarly, little attention seems to have been given in the international literature to the investigation of the adoption of open-source software by SME and by software development companies in particular. An exception is Lamastra's (2009) study of 134 Italian small and medium ISD companies, which reports that open-source solutions tended to be more innovative than their proprietary counterparts. Ploski et al.'s (2007) paper on open-source software development with version control in small enterprises also addresses ISD processes supported by open-source platforms in SME. Lee, Olson and Lee (2009) took a different path, although similar to Carvalho and Campos's (2009), and addressed the adoption of open-source ERP systems by small businesses. They point that increased adaptability, decreased dependence on a single supplier, and reduced costs seem to be the main benefits obtained by SME when they opt for an opensource solution. Moreover, in line with the arguments previously presented in this paper, the authors suggest that the diffusion of Web Services is extremely important to the development of process-oriented IT infrastructures in small companies. In their opinion, WS can lead to innovation and openness in ERP systems, as these become akin to a collection of components that can be assembled by companies as needed, over the Internet.

\section{RESEARCH METHODOLOGY}

In order to explore the difficulties, costs, benefits and critical success factors of the adoption of open-source Web Service development platforms by SME in emerging economies, the authors conducted an action research (e.g., Thiollent, 1997; Baskerville \& Wood-Harper, 1996; DeLuca, Gallivan \& Kock, 2008) in a small Brazilian software house, herein denominated JGSoft. Thiollent (1986) defines action research as:

a kind of empirically based social research that is designed and carried out in close association with an action or solution of a collective problem, in which researchers and participants that are representative of that specific situation or problem are involved in a cooperative and participatory fashion. (Thiollent, 1986, p.14)

The reason for selecting the action research methodology in our investigation was threefold. First, action research is based on the interpretive principles that substantiate the development of a contextualized view of social and organizational phenomena (Klein and Myers, 1999). To the extent that they involve people and their interactions in dynamic social-historical contexts, the introduction of IT in organizations and the development of information systems are eminently social phenomena (e.g., Baker, 2000; Grant \& Ngwenyama, 2003). Detailed knowledge of how such phenomena unveil over time can better be obtained through historical and social constructions that have as their background the organizational context in which they occur (Klein and Myers, 1999).

Second, action research is a collaborative process that is centered on the dynamic relationship between theory and practice, which requires that both be considered jointly 
during the course of a project (Baker, 2000). Action research encourages researchers to explore the phenomenon of interest not only by observing it, but also by intervening and reflecting on the effects of their interventions, from both practice and theory-driven standpoints (Avison et al., 1999). To the extent that it aims at helping participants solve their actual problems, action research helps researchers overcome the gap between rigor and relevance that has been frequently criticized in the scholarly Information Systems literature (e.g., Desouza et al., 2006).

Third, action research methodology has been used successfully in several IS studies (e.g., Baskerville \& Myers, 2004). In particular, it has been recently applied to investigate software development processes in a variety of contexts (e.g., Cunha \& Figueiredo, 2006; Grant \& Ngwenyama, 2003; Iversen, Mathiassen \& Nielsen, 2004). For this reason, as well as those described in the previous paragraphs, it seems to fit adequately the inherently exploratory goal of our research, that is, to assess the barriers, critical success factors and outcomes of the adoption of an open-source WS development platforms by a small Brazilian software house (JGSoft).

Some of JGSoft's main customers were small accounting firms. In general, those firms' core business process consisted of gathering their clients' invoices and bills, registering the correspondent transactions in the appropriate accounting books, and calculating due taxes. At the end of each month, a detailed balance sheet report of all accounting activities was generated and sent to the clients by mail. In 2006, JGSoft partnered with one of its main customers to develop an accounting system that would enable the firm's clients to obtain such reports over the Internet.

Although JGSoft had a strong record of software development using the traditional three-layer architecture, the owner thought that it was important to develop in-house expertise on SOA and WS. In line with arguments and results described in the academic and practitioner-oriented literatures (e.g., Ray \& Ray, 2006; Yen, 2006), he believed that SME could derive strategic benefits from adopting web services. Having acted as consultant to JGSoft before, one of the authors was contacted and agreed to act as the overall project manager. In such capacity, he was directly involved in negotiations with customers, systems analysis and design, and the hiring process. His position also allowed him to collect qualitative data through conversations, email messages, project documentation, direct observation, and formal interviews with all stakeholders. Seizing the opportunity, the authors obtained permission of the company's owner to carry out the development initiative as an action research project.

As described in the action research methodology (e.g., McKay \& Marshall, 2001; Thiollent, 1997), the first step was to review the relevant literature, including references on the WS architecture, SME's competitiveness, open-source software adoption, and ISD success factors. The following table summarizes the results of the searches that we conducted in online databases, such as EBSCO, ScienceDirect, and Scielo. 


\begin{tabular}{|c|c|c|c|c|r|}
\hline Country & $\begin{array}{l}\text { Scholarly } \\
\text { Journal } \\
\text { Articles }\end{array}$ & $\begin{array}{l}\text { Conference } \\
\text { Proceedings }\end{array}$ & Books & $\begin{array}{l}\text { Other } \\
\text { Documents }\end{array}$ & Total \\
\hline Brazilian & 7 & 0 & 0 & 4 & $\mathbf{1 1}$ \\
\hline International & 25 & 4 & 3 & 9 & $\mathbf{4 1}$ \\
\hline Total & $\mathbf{3 2}$ & $\mathbf{4}$ & $\mathbf{3}$ & $\mathbf{1 3}$ & $\mathbf{5 2}$ \\
\hline
\end{tabular}

Table 1. Profile of literature search results

Information obtained in the literature was complemented with data collected in interviews with five experienced developers, and used to identify potential critical success factors (CSF) of the adoption of an open-source WS architecture (e.g., Wasmund, 1993; Rothenberger et al., 1998; Reel, 1999). To assess the results of the project, the authors defined performance criteria that captured the essential aspects of the ISD process and its results (e.g., Colombo \& Guerra, 2002).

The research proceeded as follows over a period of approximately one and half years:

1. The researcher that acted as project leader selected, obtained and installed the necessary open-source WS development tools and class libraries.

2. JGSoft's new WS-based ISD environment was created and checked using some of the examples that were included in software libraries. Tests conducted in the development environment and in the Internet verified the WS examples' conformity and quality.

3. The functionalities of the new accounting system were defined based on their complexity and usefulness from the customer's standpoint.

4. Systems analysis and programming tasks were initiated and conducted as follows:

a. The researchers published a website in the Internet to promote the project and invite other developers to join it. Guidance materials on WS were developed and made available to help newcomers get up to speed with the technology, the project and the open-source ISD platform.

b. The researcher acting as project leader recruited, selected and hired developers to participate in the ISD process.

c. Example WS were made available in the Internet, so that developers could carry out tests.

d. The first WS modules were developed. Their model was made available to selected partners (other ISD companies), so that they could make comments and suggestions. Their input was documented and used to make adjustments in the development process and its results. 
e. The WS modules were completed, installed and evaluated. The assessment of each released module and the analysis of its development process were used not only to promote adjustments in the ISD methodology and the software framework, but also to identify potential barriers and success factors for the adoption of an open-source WS development platform. In this way, the iterative nature of the action research method, which progresses through planning-acting-evaluating and reflection cycles, was an essential characteristic of our study.

5. Software quality and ISD productivity criteria were used to check if there was any improvement in relation to previous architectures used by JGSoft.

6. The literature on WS and open-source software were used to identify critical success factors of web services development processes. To assess if they would apply to the context of a small ISD company, the authors conducted in-depth interviews with five directors of small and medium-sized Brazilian software houses which had vast experience in software development projects. The revised set of critical success factors was then aggregated into categories according to their similarity. Finally, the resulting categories were compared against the events and characteristics of the JGSoft's project that were considered essential to the success of their initiative.

Data analysis was overseen by the author who had no direct involvement in the ISD project. It consisted mainly of coding textual data and developing, relating and integrating themes and categories that emerged from the iterative analysis process. The latter author critically assessed his peer's interpretation of events, offering alternative meanings and suggesting new venues to be explored in the ISD project. Both researchers were constantly aware of the possibility of the introduction of bias in their analysis, given the role one of them played in the project. From time to time, participants in JGSoft and its customer were asked to check the authors' interpretations, so that they correctly represented the participants' point of view.

\section{RESULTS OF THE ACTION RESEARCH PROJECT}

\section{JGSoft's WS Development Project}

To reduce development costs, the project leader assembled a software framework consisting of Borland Kylix 3 Open Edition, the Mandrake Linux operating system, the Apache web server, FreeCLX and ZeosDB libraries for database access, and IndySOAP for the SOAP/XML interface. The following issues guided the selection process: (1) JGSoft project developers' lack of knowledge on Java and .NET development tools; (2) their large previous experience with Object Pascal and Borland development environment; (3) and the company's lack of financial resources to invest in proprietary solutions and training. The selection of Kylix allowed the developers to use the programming language that they were most familiar with, thereby helping them ease the transition to WS technology. As a result, project completion time could be shortened and no investments in training and hiring new developers would be necessary. These benefits are certainly significant to small software houses such as JGSoft, which normally have to conduct their projects under strict budget limitations and tight schedules. In fact, in JGSoft's case, the ISD project would not be viable without the use of open-source software. The expenses with licenses of proprietary development tools 
by themselves would exceed the total price charged for the project.

Initially, the project team consisted of the project leader (one of the authors), a programmer and a web designer. At that time, all developers were very confident and excited about participating in the project. Besides being motivated by the fact that they could try new ways to develop a system, they also realized it was possible to synchronize WS class modeling and physical implementation, which would make the development tasks much easier and "a lot more elegant".

Nonetheless, the team had some difficulty adapting to the Linux operating system. All of them were used to working in the MS Windows environment. Simple issues such as the lack of shortcut keys and visual resources created considerable discomfort. Although these adaptation problems had a negative impact on the team's productivity, they were overcome by most developers in the first month of the project.

Later, still during the system analysis phase and after a long search, two other developers that were capable of working with the chosen platform were hired. The difficulty finding Kylix developers was seen as a natural consequence of the increasing adoption of Java and .NET by Brazilian programmers (e.g., Cesar, 2003; Yuri, 2008). Although the project leader developed and published tutorials and ancillary materials in a website to encourage developers to join the project, recruiting team members proved to be quite hard. In spite of this, JGSoft decided to continue to use Kylix to avoid further delays in the project.

Team members soon perceived they could work more independently when modeling the system architecture. The inherent modularity of WS technology made possible to separate the graphic interface from the business rules. As a result, the project itself, as well as the related specifications, was clearer and easier to understand. Although developers believed that this could have a positive impact on software quality, their newly acquired relative independence gave way to some heated discussions. Some of them argued that if a single service interface (parameter definition and new method definitions) had to be altered, all others would have to be compiled and tested again, and this would generate delays and increase costs. Since no consensus was achieved on this issue, it was then agreed that the developers would simulate changes in the business rules to see what kind of adjustments and tests would have to be made in the system and also how they compared to similar situations in the old ISD architecture.

Technical problems were often faced by the project team. For instance, there were incompatibilities among Kylix, Mandrake Linux and the Apache web server. Also, it was necessary to convert the libraries and correct bugs so that they could be used with the chosen open-source development platform. Although developers recognized they gained important knowledge during this process, the project was delayed by four months. The team also faced problems related to securing access to the services and the way WS management was supposed to be implemented. The standards for WS security were not yet published at that time and there were no tools available to implement the corresponding security layers. Consequently, the developers had to come up with their own proprietary solution, which they knew would probably not conform to prospect W3C standards. JGSoft saw no alternative but to accept the risk of having to rewrite their software modules in the future to ensure compatibility and interoperability.

One and half years after the beginning of the project, JGSoft's WS-based system 
was fully tested and installed in the accounting firm's premises. The customer attested that it met all requirements and successfully supported its new business process. Overall, the project involved eight people, including programmers, web designers, consultants and suppliers, and cost about US\$ 15,000. More than 40,000 lines of code were generated, and eight web services were published. Furthermore, due to compatibility issues and bugs, the project team had to maintain over 200,000 lines of code of auxiliary libraries, such as Indy, IndySOAP, Zeos and Web Provider. Although it was still necessary to develop the final front-end programs to access the services, the project was considered a success by all parties involved.

\section{ISD Performance Criteria}

Although both JGSoft and its client agreed that the project was successful, the researchers felt it was necessary to define more consistent and encompassing criteria to check if the adoption of the new WS development platform generated any improvement in relation to previous architectures used by the software house. This was an important step not only in the assessment of the outcomes of the adoption process, but also in the identification of related critical success factors.

Three main aspects were contemplated by in the definition of ISD performance criteria: the quality of the product; the costs of the development process; and the productivity level achieved in the development activities. Product quality refers to the degree to which the developed system meets customer's expectations, while cost and productivity are directly connected to profitability. Therefore, the adopted criteria attempted to measure elements that are critical to SME's competitiveness and survival.

Current research on software quality has usually drawn on perspectives put forth in ISO/IEC 9126 (e.g., Colombo \& Guerra, 2002; Bhatti, 2005). The same approach has also been adopted by the Brazilian Software Quality Study Commission to evaluate new IS architectures and software. The following ISO/IEC categories were assessed in this study: needs.

- Functionality: the degree to which the system meets clients'

- Reliability: how flawless the system is and how resilient it is when problems occur. It takes into consideration recovery capabilities (e.g., the time needed to recover information that has been lost) and how long the system works uninterruptedly (i.e., time between failures).

- Usability: how easy it is for users to work with the system.

- Efficiency: how effective the system is, i.e., the relation between consumption of computer resources and the functionalities implemented in the system.

- $\quad$ Maintainability: the level of complexity and flexibility involved in introducing new features in a system or adjusting it to correct defects or cope with changes in its environment.

- Portability: how adaptable and independent of specific technology the system is, i.e., how easy it is to move the system to different platforms of hardware and software.

The second group of criteria focused on profitability. Given the scarcity of 
resources and turbulence that characterize SME's business environment, it is important for small ISD companies in emerging economies to be able to correctly estimate and control the development costs associated with their architectures (e.g., basic hardware and software, development tools, people). Furthermore, to reduce costs, they must strive to increase productivity, which can be achieved by making software code as reusable as possible. Reusability refers to how much of a code can be used to build different systems (Coad \& Yourdon, 1991). By reusing code, developers can not only increase productivity, but also improve the quality of their software (Coad \& Yourdon, 1991; Rothenberger, 1998). Therefore, total cost and degree of reusability were also chosen as criteria to evaluate JGSoft's project.

\section{Critical Success Factors of WS-Based ISD Processes}

A review of the literature on WS and ISD (e.g., Boehm, 1994; Booch, 2001; Reel, 1999; Stal, 2003; Wasmund, 1993; W3C, 2001; Yen, 2006) revealed a number of potential critical success factors (CSF) for WS-based ISD processes. As explained before, they were revised and complemented with data collected in in-depth interviews with five directors of small and medium Brazilian software houses. The final list of the potential CSF that resulted from this analysis is presented below.

- $\quad$ Adoption of appropriate development tools: usability, efficiency and functionality, as well as associated costs, must be aligned with the project's goals, requirements, team expertise, and budget.

- $\quad$ Adequate team of developers: developers must be motivated and have a level of expertise and experience in ISD that is compatible with the complexity of the project.

- Formalization of unitary tests: tests must be adequately performed to ensure software quality. They may have a direct impact on reliability, as long as they help eliminate errors that hinder system's operation.

- WS publication: publication of the WS modules and related information using appropriate standards and channels is essential to ensure their quality and consistent usage.

- Interoperability: WS must meet the established standards and interact with any compliant application and platform. Interoperability improves software portability and maintainability.

- $\quad$ Incremental maintenance: WS implementation must ensure that adjustments in specific modules can be easily accomplished without compromising the rest of the system. Incremental maintenance improves maintainability and reliability, insofar as it minimizes system maintenance downtime.

These critical success factors were used to structure the analysis of the data collected in the action-research, as JGSoft's experiences were evaluated to unveil barriers, success factors and outcomes of the ISD project, and its findings compared to the extant literature. The next section summarizes the corresponding results. 


\section{Barriers, Success Factors and Outcomes of JGSoft's Project}

The analysis of the events that took place at JGSoft and the associated qualitative data suggests that the adoption of the new open-source WS development platform allowed the company to significantly improve its ISD processes. Table 2 synthesizes our findings. In its rows, the CSF listed in the previous section were used to aggregate into categories the success factors we were able to identify in our analysis. Elements of JGSoft's experience were deemed a CSF when they seemed to have had a crucial impact on one or more of the aforementioned performance criteria, from the standpoint of the company's owner and the project team. The ISD criteria were placed in the columns of the table.

In the intersection a row and a column, a positive/negative sign (+/-) indicates a significant improvement/deterioration of the corresponding performance criterion (in comparison with the previous situation in JGSoft), as a result of the elements of the project that are subsumed in the corresponding row. Most criteria showed positive gains; those that apparently deteriorated tend to reflect the characteristics of the development tools employed in the project, rather than problems of the WS technology itself. These results are discussed in the subsequent paragraphs.

\begin{tabular}{|l|l|l|l|l|}
\hline CSF / project characteristics and events & \\
Development tools: the inherent characteristics \\
of the WS technology allowed the achievement of \\
several of the expected benefits; the necessity of \\
adjusting the source code of open-source tools and \\
libraries made it harder to implement the required \\
functionalities and to maintain the code.
\end{tabular}




\section{CSF / project characteristics and events}

Tests formalization: the well-designed interface and inherent modularity of WS made it easy to create testing programs that covered most of the functionalities of each service; by ensuring software quality, the tests also enhanced the reusability of the services.

WS publication: constant communication with developers' communities helped the team to solve technical problem and advertise the developed web services; most developers did not speak Portuguese, which made the contacts harder for the JGSoft team.

Interoperability: despite the industry's problems in interpreting and implementing the WS standards, the new architecture improved interoperability beyond the levels achieved with the previous client/server architecture; the possibility of easily interacting with other systems and platforms increased the system's portability and made it easier to add new functionalities.

Incremental maintenance: the WS architecture and platform used in the project were very flexible and ease to use, as far as implementing changes in the services; the lack of rigor in implementing the WS standards and the constant updates of different technologies generated conflicts when the new WS versions were installed.

Table 2. CSF and Performance Criteria in JGSoft's Project

Improved interoperability is one of the main goals of SOA. However, there was a gap between the literature and the open-source tools, techniques and practices that were available to developers in JGSoft. For example, several of the WS standards published at the time had not yet consolidated in the IS community, as they were interpreted differently by developers. This lack of rigor on standards implementation is prone to result in problems observed in previous architectures that succumbed to their own incompatibilities (cf. Stal, 2003). Paradoxically, it is usually argued in the literature that web services are effectively used only when they are reused and shared among people and organizations (e.g., Lee, Olson \& Lee, 2009; W3C, 2004). In fact, the authors did want to find other organizations that could be interested in using the WS developed by 
JGSoft, so that they could evaluate whether the reuse and sharing of the published services could generate further benefits. Nevertheless, the accounting firm did not grant them permission to do this. This attitude is consistent with reports that indicate that most organizations do not take real financial advantage from their own web services and use them merely to reduce costs via automation and code reuse (e.g., CIOL, 2007; BNET, 2005). However, especially for SME in emerging economies, financial benefits obtained with WS could represent significant revenue increases and competitiveness gains, thereby increasing their chances of survival.

JGSoft's decision to use a free, open-source development platform contributed in several ways to the ISD project, suggesting that such alternative can provide considerable benefits to small and medium-sized ISD companies. Nevertheless, its daily usage proved to be more complex than initially expected. Open-source software is usually in constant, unrestricted evolution, as its community of developers continuously adds new features and corrects bugs. One of the most important findings of this research is that ISD companies that intend to employ open-source technology should plan ahead and allocate appropriate resources to enable its project teams to engage effectively in the development process of the tools they will eventually use. Thus, one should keep in mind that, typically, the adoption and utilization of "free" development software is not actually free of costs. To use it effectively, companies may have to incur expenses related to testing, improving and supporting software code and documentation, and further training their own employees.

On the other hand, the need to correct conflicts and bugs in the free, open-source software provided developers with an opportunity to acquire in-depth knowledge of their development technologies. This is regularly not possible when proprietary software is used. By having access to the tools and libraries' source code and directly contacting its authors to ask questions and make suggestions, developers were able to better understand XML, WS and the SOA architecture. In this way, they acquired experience and skills whose usefulness went beyond the scope of the project at hand and would probably spill over to other initiatives. This result is in line with reports found in the literature regarding the achievement of important additional benefits from the participation in open-source communities, such as the acquisition of critical knowledge and expertise, and the faster and less expensive improvement and innovation of products (e.g., Lamastra, 2009; Lee, Olson \& Lee, 2009; Santos Jr, 2010). The intellectual capital thus obtained by JGSoft may prove to be an important strategic resource to create business value for the company (Grant, 1996; Patnayakuni, Rai \& Tiwana, 2007).

\section{CONCLUSION}

JGSoft's experiences suggest that WS architecture offers interesting opportunities for small and medium-sized software development companies. More than supporting improvements in systems development processes and outcomes, in terms of quality, costs and productivity, WS can be used strategically to develop new products and services and attract new customers. The complexities involved in using an open-source development platform can also be seen as an opportunity to develop in-house capabilities that boost the company's capacity to adapt, innovate and compete. In emerging economies, where markets tend to be volatile and resources scarce, such intangible assets may prove essential to SME's survival. Nevertheless, even an opensource WS platform tends to require some level of investment. To be successful, SME 
must be prepared to allocate human, technological and financial resources before they can obtain the expected benefits of the adoption of open-source ISD technologies.

Research on WS adoption and IS development in SME could also benefit from this study. First, its findings highlight the importance of knowledge-management practices to the development of innovation in the dynamic, unstructured environments that characterizes small software houses (cf. Matiassen \& Vainio, 2007). Absorptive capacity (Cohen and Levinthal, 1990), that is, an organization's capacity to identify relevant external knowledge, absorb it and apply it internally, seems to be especially critical in this context. Future empirical studies should try to assess the effects of this capacity on the performance of the ISD process in small software developers, especially in association with IT (e.g., infrastructure, governance practices) and other organizational resources and capacities (e.g., managerial capacity, organizational structure, market orientation). Such pursue would be in line with the concepts and propositions put forth by authors such Nevo and Wade (2010).

Second, our research pointed out the vital role played by SME project leaders in the adoption of new technologies. Over the course of the project at JGSoft, a number of barriers emerged. Due to the lack of resources and structure faced by the development team, the company's owner had to take the responsibility for generating flexible, creative, inexpensive solutions that allowed the company to keep the project on track. Further research is necessary to develop our understanding of the impact of leadership characteristics on the success of ISD projects in SME. Although the literature on leadership is extensive, several authors (e.g., Cragg, Caldeira \& Ward, 2011; Richardson \& von Wangenheim, 2007) argue that organizational theories built from the perspective of a large enterprise may not be suitable in this context.

In spite of the measures taken by the researchers to improve the validity of the findings described in this paper, it is important to keep in mind that the action research project conducted at JGSoft was exploratory and qualitative by nature, thereby possibly being subject to interpretation bias. Given the paucity of the scholarly literature on the topics of this investigation, we feel that our findings do contribute to shed light on practices and potential benefits and barriers associated with the adoption of open-source WS-based ISD platforms by small software houses. Nevertheless, their generalizability must be put to the test by studies conducted in different organizational contexts and involving different technologies. The combination of the results obtained may be used in the future to define and operationalize constructs and assess their causal relationships statistically. 


\section{REFERENCES}

Asfoura, E., R. Neumann, et al. (2011). The identifying and adapting of FERP mall form and roles for more trust by marketing of distributed FERP components. Procedia Computer Science, 3(0): 11-22.

Avison, D., Lau, F., Myers, M. \& Nielsen, P. A. (1999) Action Research. Communications of the ACM 42(1): 94-97.

Baker, C. R. (2000) Towards the increased use of Action Research in accounting information systems. Accounting Forum 24(4): 366-378.

Balestrin, A. \& Vargas, L.M. (2004). A dimensão estratégica das redes horizontais das PMEs: Teorizações e Evidências. Revista de Administração Contemporânea, 8, 203227.

Baskerville, R. \& Myers, M. D. (2004). Special Issue on Action Research in Information Systems: Making IS Research Relevant to Practice - Foreword. MIS Quarterly 28(3): 329-335.

Baskerville, R.L. \& Wood-Harper, T.A. (1996). A critical perspective on action research as a method for information systems research, Journal of Information Technology, 11, 235-246.

Bhatti, S. N. (2005). Why quality? ISO 9126 software quality metrics (functionality). support by UML suite, SIGSOFT Softw. Eng. Notes, 30 (2): 1-5.

BNET (2009). Web Services Authentication Still a Home-Grown Affair; Authentication Remains the Biggest Problem for Web Services Security. FindArticles.com. Retrieved from http://findarticles.com/p/articles/mi_m0EIN/is_2005_June_13/ai_n13808910/

Boehm, B. (1994). Software Architectures: Critical Success Factors and Cost Drivers. Proceedings of the 16th International Conference on Software Engineering. Association for Computing Machinery (ACM).

Booch, G. (2001). Web Services: The Economic Argument. Dr.Dobb's - The World of Software Development. Retrieved from http://drdobbs.com/architecture-anddesign $/ 184414785$

Brasil (2011). Software livre no governo do Brasil. Retrieved from http://www.softwarelivre.gov.br

Carvalho, R. A. \& Campos, R. (2009). Uma análise de aspectos relacionados ao desenvolvimento e adoção de Enterprise Resources Planning livre de código aberto.

Gestão \& Produção, 16 (4). Retrieved from http://www.scielo.br/scielo.php?script=sci_arttext\&pid=S0104530X2009000400014\&lng=en\&nrm=iso

Cesar, R. (2003). Java X .Net: disputa acirrada no mercado nacional. Computerworld. Retrieved from http://computerworld.uol.com.br/tecnologia/2003/06/17/idgnoticia.2006-05$15.5204280289 /$

CIOL (2007). Developers prefer Java for implementing SOA. EDC. Retrieved from http://www.ciol.com/Languages/Feature/Developers-prefer-Java-for-implementing$\underline{\text { SOA-EDC/2280799238/0/ }}$ 
Clabby, J. (2002). Web Services Explained: Solution and Applications for the Real World. New York: Prentice Hall.

Coad, P.\& Yourdon, E. (1991). Object-oriented design. New Jersey: Yourdon Press.

Cohen, W. \& Levinthal, D. (1990). Absorptive Capacity: A New Perspective on Learning and Innovation. Administrative Science Quarterly 35(1), 128-152.

Colombo, R. \& Guerra, A.C. (2002). The Evaluation Method for Software Product. ICSSEA '2002 - International Conference Software \& Systems Engineering and their Applications, Paris, France.

Cragg, P., Caldeira, M. \& Ward, J. (2011). Organizational information systems competences in small and medium-sized enterprises. Information \& Management 48(8): 353-363.

Cunha, P. R. \& Figueiredo, A. D. (2006). A Tale of Action research in Information Systems: Memories of a Ph.D. Student. Communications of AIS 17: 2-36.

DeLuca, D., Gallivan, M. J. \& Kock, N. (2008). Furthering Information Systems Action Research: A Post-Positivist Synthesis of Four Dialectics. Journal of the Association for Information Systems 9(2): 48-71.

Desouza, K. C., El Sawy, O. A., Galliers, R. D., Loebbecke, C. \& Watson, R. T. (2006). Beyond Rigor and Relevance towards Responsibility and Reverberation: Information Systems Research That Really Matters. Communications of AIS 17(16): 2-26.

Dumout, E. (2004). Windows to Linux switch - Munich's mayor speaks. Silicom.com. Retrieved from http://www.silicon.com/technology/software/2004/08/06/windows-tolinux-switch-munichs-mayor-speaks-39122965/

Enders, A., Hungenberg, H. et al. (2008). The long tail of social networking: Revenue models of social networking sites. European Management Journal 26(3): 199-211.

Felix, J. H. S. et al. (2009). Avaliação computacional de enfisema pulmonar em TC: comparação entre um sistema desenvolvido localmente e um sistema de uso livre. $J$. Bras. Pneumol., 35(9). Retrieved from http://www.scielo.br/scielo.php?script=sci_arttext\&pid=S180637132009000900008\&lng=en\&nrm=iso

Fitzgerald, B. (2006). The transformation of open source software. MIS Quarterly, 30(3): 587-598.

Fitzgerald, B.\& Kenny, T. (2003). Open Source Software in the Trenches: Lesson from a Large-Scale OSS implementation. $24^{\text {th }}$ International Conference on Information Systems, Seattle, WA, United States.

Forte, M., W. L. de Souza, et al. (2008). Using ontologies and Web services for content adaptation in Ubiquitous Computing. Journal of Systems and Software 81(3): 368-381.

Grant, D. \& Ngwenyama, O. (2003) A report on the use of action research to evaluate a manufacturing information systems development methodology in a company.

Information Systems Journal 13(1): 21-35.

Hagel, J.\& Brown, J.S. (2004). TI Flexível, a melhor estratégia. HSM Management, 43.

Henrikson, J. E. (2011). The Growth of Social Media: An Infographic. Search Engine Journal. Retrieved from: http://www.searchenginejournal.com/the-growth-of-socialmedia-an-infographic/32788/. 
Hinkka, V., J. Holmström, et al. (2009). Building Identity-Based Tracking and WebServices for SMEs. International Journal of e-Business Management 3(1): 49-54.

IBGE (2006). Pesquisa Anual de Serviços. Instituto Brasileiro de Geografia e Estatística (IBGE). Retrieved from http://ibge.gov.br/home/estatistica/economia/comercioeservico/pas/pas2006/pas2006.pd $\underline{\mathrm{f}}$

Iversen, J. H., Mathiassen, L. \& Nielsen, P. A. (2004). Managing Risk in Software Process Improvement: An Action Research Approach. MIS Quarterly 28(3): 395-433.

Iyer, B., Freedman, J., Gaynor, M., Wyner, G. (2003). Web Services: Enabling Dynamic Business Networks, Communications of the AIS, 11, 525-554.

Jordan, M., Nohama, P., Britto Junior, A. S. (2009). Software livre de produção textual com predição de palavras: um aliado do aluno especial. Rev. Bras. Educ. Espec., 15(3). Retrieved from http://www.scielo.br/scielo.php?script=sci_arttext\&pid=S1413$\underline{65382009000300004 \& \operatorname{lng}=\mathrm{en} \& \mathrm{nrm}=\mathrm{iso}}$

Kavanagh, J. F. (2004). Resistance as motivation for innovation: Open Source Software. Communication of the AIS, 13, 615-628.

Klein, H. Z. \& Myers M. D. (1999) A set of principles for conducting and Evaluating Interpretive Field Studies in Information Systems. MIS Quarterly 23(1): 67-94.

Kreger, H. (2003). Fulfilling the Web Services Promise, Communications of the ACM, 46(6): 29-34.

Krill, P. (2008). SOA adoption slows in '08. InfoWorld, 2008. Retrieved from http://www.javaworld.com/javaworld/jw-11-2008/jw-11-soa-in-a-slump.html.

Lamastra, C. R. (2009). Software innovativeness. A comparison between proprietary and Free/Open Source solutions offered by Italian SMEs. $R \& D$ Management, 39(2): 153-169.

Lee, S. M., Olson, D. L. \& Lee, S.-H. (2009). Open process and open-source enterprise systems. Enterprise Information Systems, 3(2): 201-209.

Li, Z., N. Alaeddine, et al. (2010). Multi-faceted quality and defect measurement for web software and source contents. Journal of Systems and Software 83(1): 18-28.

Lim, B. \& Wen, H. J. (2003) Web Services: An analysis of the technology, its benefits, and implementation difficulties. Information Systems Management Journal 20(2): 4957.

Mathiassen, L. \& Vainio, A. M. (2007). Dynamic Capabilities in Small Software Firms: A Sense-and-Respond Approach. IEEE Transactions on Engineering Management 54(3), 522-537.

McKay, J. \& Marshall, P. (2001). The Dual Imperatives of Action Research. Information Technology and People, 14(1): 46-59.

Netcraft (2011). June 2011 Web Server Survey. Netcraft. Retrieved from http://news.netcraft.com/archives/2011/06/07/june-2011-web-server-survey.html

Nevo, S. \& Wade, M. R. (2010). The Formation and Value of IT-Enabled Resources: Antecedents and Consequences of Synergistic Relationships. MIS Quarterly 34(1): 163183.

Papazoglou, M. P. \& Heuvel ,W.-J. (2007). Service oriented architectures: approaches, 
technologies and research issues. The VLDB Journal - The International Journal on Very Large Data Bases, 16(3): 389-415.

Paredes-Valverde, M. A., G. Alor-Hernández, et al. (2012). Developing Social Networks Mashups: An Overview of REST-Based APIs. Procedia Technology 3(0): 205-213.

Patnayakuni, R.\& Rai, A.\& Tiwana, A. (2007). Systems development process improvement: a knowledge integration perspective. IEEE Transactions on Engineering Management, 54, 2, 286-300.

Ploski, J., Hasselbring, W., Rehwinkel, J. \& Schwierz, S. (2007). Introducing Version Control Database-Centric Applications in a Small Enterprise. IEEE Software, 24(1): 3844.

Pookulangara, S. \& Koesler, K. (2011). Cultural influence on consumers' usage of social networks and its' impact on online purchase intentions. Journal of Retailing and Consumer Services 18(4): 348-354.

Ray, A. W. \& Ray, J. J. (2006). Strategic benefits to SMEs from third party web services: An action research analysis. Journal of Strategic Information Systems, 15(4): 273-291.

Reel, J. S. (1999). Critical success factors in software projects, IEEE Software, 16, 1823.

Richardson, I. \& von Wangenheim, C. G. (2007). Guest Editors' Introduction: Why Are Small Software Organizations Different? IEEE Software 24(1): 18-22.

Roloff, M. L. \& Oliveira, R. A. (2007). Um modelo competitivo baseado em ferramentas software livre para a gestão tecnológica de organizações: a promoção do conhecimento corporativo e da inovação tecnológica em uma graduação tecnológica. $J$. Information Systems and Technology Management, 4(2). Retrieved from http://www.scielo.br/scielo.php?script=sci_arttext\&pid=S1807$17752007000200002 \& \operatorname{lng}=e n \& n r m=$ iso

Rothenberger, M., Kulkarni, U. \& Dooley, K. (1998). Critical Success Factors for Software Reuse Projects. International Conference on Information Systems, Helsinki, Finland.

Santos Jr, C. (2008). Understanding partnerships between corporations and the open source community: a research gap. IEEE Software, 25(6): 2008.

Santos Jr, C. (2010). Atratividade de projetos de software livre: importância teórica e estratégias para administração. Rev. Adm. Empres., 50(4). Retrieved from http://www.scielo.br/scielo.php?script=sci_arttext\&pid=S003475902010000400007\&lng=en\&nrm=iso

Santos, S. R. (2010). Informática em enfermagem: desenvolvimento de software livre com aplicação assistencial e gerencial. Rev. Esc. Enferm. USP, 44(2). Retrieved from http://www.scielo.br/scielo.php?script=sci_arttext\&pid=S0080$\underline{62342010000200008 \& \operatorname{lng}=e n \& n r m=i s o}$.

SEBRAE-SP (2009). As micro e pequenas empresas na economia. SEBRAE-SP, 2009. Retrieved from http://www.sebraesp.com.br/conhecendo_mpe/mpe_numero/pequena_empesa_economi $\underline{\mathrm{a}}$ 
Sleeper, B. (2001). Defining Web Services. San Francisco: The Stencil Group.

Stal, M. (2003). Web services: beyond component-based computing. Communications of the ACM, 45(10): 71-76.

Stallman, R. The Free Software Definition. Retrieved from http://www.gnu.org/philosophy/free-sw.html

Sultan, N. A. (2011). Reaching for the "cloud": How SMEs can manage. International Journal of Information Management 31(3): 272-278.

Thiollent, M. (1997). Pesquisa-Ação nas Organizações. Rio de Janeiro: Atlas.

US-DOJ (1994). Microsoft agrees to end unfair monopolistic practices. United States of America-Department of Justice, 94-387. Retrieved from http://www.usdoj.gov/opa/pr/Pre_96/July94/94387.txt.html .

W3C (2004). Web Services Architecture. W3C. Retrieved from http://www.w3.org/TR/ws-arch/

Wasmund, M. (1993). Implementing critical success factors in software reuse. IBM Systems Journal, 32(4): 595-611.

Yen, C. (2006). Trends of Web Services Adoption: A Synthesis. In: Khosrow-Pour, M. (ed.), Emerging Trends and Challenges in Information Technology Management, Volume 1 and Volume 2, Hershey, PA: Idea Group Inc. Retrieved from http://www.irma-international.org/viewtitle/32998/.

Yuri, F. (2008). Certificação ou especialização acadêmica? Computerworld. Retrieved from http://computerworld.uol.com.br/carreira/2008/05/15/certificacao-ouespecializacao-academica/ 
606 Moreno Junior, W. A., Gomes, J. C. 